\title{
Formações Discursivas sobre Homossexualidade e Família Homoparental em Telenovelas Brasileiras
}

\author{
Eduardo Name Risk ${ }^{1}$ \\ ${ }^{1}$ Universidade Federal de São Carlos, São Paulo, Brasil
}

\author{
Manoel Antônio dos Santos ${ }^{2}$ \\ ${ }^{2}$ Universidade de São Paulo, São Paulo, Brasil
}

\begin{abstract}
Resumo: Na história da televisão brasileira, a novela é um produto popular que adquiriu características próprias e incorporou uma série de personagens homossexuais. O objetivo deste estudo foi analisar as formações discursivas sobre homossexualidade e família homoparental em telenovelas brasileiras veiculadas em horário nobre. Foi realizada pesquisa qualitativa e estabelecidos critérios para composição do corpus a partir de cenas de três telenovelas da década de 2010, que performavam personagens homossexuais ao longo de toda a trama. As cenas selecionadas foram transladadas/transcritas. Os dados foram analisados conforme o referencial teórico dos estudos queer e dos estudos culturais. A análise demonstrou que a representação de personagens homossexuais nas novelas se apoia largamente em clichês. Se, por um lado, houve considerável incremento e diversificação dessas representações, o mesmo não ocorreu com a visibilidade em relação à família homoparental. Nota-se, assim, que a telenovela pode operar como potente instrumento de normalização e regulação das sexualidades e desejos.
\end{abstract}

Palavras-chave: Telenovela, Homossexualidade, Homoparentalidade, Teoria Queer, Estudos Culturais.

\section{Discursive Formations on Homosexuality and Homoparenthood in Brazilian Soap Opera}

\begin{abstract}
The soap opera is a popular product within the history of Brazilian television, which acquired its own features and incorporated a series of homosexual characters. This article aims to analyze discursive formations on homosexuality and homoparenthood in prime time Brazilian soap operas. This qualitative research was conducted with scenes of three 2010 s soap operas that include homosexual characters throughout their plot. Selected scenes were translated/ transcribed and analyzed in the light of queer studies and cultural studies. The results indicate that these serial programs heavily rely on stereotypes for representing homosexual characters. Despite the considerable increase and diversification in the representation of gay characters, the same did not occur with the visibility of homoparenthood. Thus, soap operas can be a powerful instrument of normalization and regulation of sexualities and desires.
\end{abstract}

Keywords: Soap Opera, Homosexuality, Homoparenthood, Queer Theory, Cultural Studies.

\section{Formaciones Discursivas sobre Homosexualidad y Familia Homoparental en Telenovelas Brasileñas}

Resumen: En la historia de la televisión brasileña, la telenovela es un producto popular, que adquirió características propias e incorporó una serie de personajes homosexuales. Este artículo pretende analizar las formaciones discursivas sobre homosexualidad y familia 
homoparental en telenovelas brasileñas, vehiculadas en la hora de mayor audiencia. Se realizó una investigación cualitativa y se estableció criterios para la composición del corpus a partir de escenas de tres telenovelas de la década de 2010 que tuvieran personajes gais en la trama. Las escenas seleccionadas fueron trasladadas/transcritas. Los datos se analizaron conforme el referencial teórico de los estudios queer y de estudios culturales. El análisis demostró que la representación de personajes homosexuales en las telenovelas se apoya ampliamente en clichés. Por un lado, hubo considerable aumento y diversificación de las representaciones de personajes gais, por otro, lo mismo no ocurrió con la visibilización de la familia homoparental. Se observa que la telenovela puede ser potente instrumento de normalización y regulación de las sexualidades y los deseos.

Palabras clave: Telenovela, Homosexualidad, Homoparentalidad, Teoría Queer, Estudios Culturales.

Em dezembro de 1951, pouco mais de um ano após a implantação da televisão no Brasil, a primeira telenovela começou a ser exibida. Desde então, as novelas difundem discursos e práticas que, junto a outras mídias, segmentam a subjetividade, um processo que se acentuou notavelmente nos anos 1970 com o aperfeiçoamento da teledramaturgia brasileira e sua consolidação como produto industrial de exportação, catapultando a supremacia da Rede Globo de Televisão como a maior emissora do país. Se o apogeu do gênero ocorreria nos anos 1980-1990, a partir dos anos 2010, com o advento das plataformas digitais e serviços de streaming, outras produções - séries, por exemplo - têm concorrido pela audiência que, até então, era cativa e fiel seguidora das telenovelas.

No formato que assumiram nesses 70 anos de existência, as telenovelas são um amálgama de discursos que, de um lado, buscam distender práticas e representações relacionadas a temáticas moralizantes - sexualidade e gênero, por exemplo -, e por outro, hibridizam-se com discursos hegemônicos sobre essas temáticas (Hamburger, 2005, 2011). Por ser formatada segundo gênero próprio (Pallottini, 2012; Sadek, 2008) e permeada por interesses econômicos e políticos, a telenovela, obra aberta, reorganiza essas temáticas que se encontram na corda-bamba, ora cedendo ao pensamento convencional, ora confrontando hegemonias ao funcionar como caixa de ressonância das tensões sociais do país.

Segundo os estudos culturais, valores, costumes e estilos de vida que contestam padrões estabelecidos - ou seja, diferenças existentes no âmbito das relações de gênero e da sexualidade, dentre outras podem ser lucrativos, quando segmentados pela cultura da mídia que garimpa novidades com o intuito de difundir novos estilos de vida junto ao grande público (Kellner, 2001). Para tanto, a telenovela descortina dra- mas privados de forma pública e vice-versa ao abrigar temáticas atinentes aos âmbitos político e doméstico, à masculinidade e feminilidade, dentre outras ordenações binárias, de modo a sintetizar, em um único produto, ficção e notícia (Hamburger, 2005).

Às asserções anteriores somam-se as proposições de Martín-Barbero (2015), representante da corrente latino-americana dos estudos culturais, para quem as mídias devem ser contextualizadas à luz de matrizes históricas, sociais e culturais. Para o autor, é preciso analisar a mediação entre matrizes culturais e formatos industriais, ou seja, explorar de que modo gramáticas discursivas da cultura popular, somadas aos movimentos sociais e discursos subalternos, articulam-se e hibridizam-se com discursos hegemônicos e com as formas técnicas/industriais de produção da cultura. Tais matrizes também são mediadas pelas relações de sociabilidade estabelecidas no cotidiano e pela institucionalidade, isto é, os interesses do Estado, que busca manter a ordem social e a estabilidade das instituições, contrapostos às forças sociais - "maiorias" e "minorias" - que buscam o reconhecimento de seus direitos e/ou sua estabilidade. A telenovela, por meio de seu enredo e de seus personagens, espelha essas conflagrações a partir de antinomias, como pobreza versus riqueza, centro versus periferia, metrópole (moderno) versus interior (arcaico), heterossexualidade versus homossexualidade etc.

Vários estudos se dedicaram a analisar a trajetória de personagens homossexuais nas telenovelas brasileiras de modo geral (LaPastina \& Joyce, 2014; Peret, 2005) ou em novelas específicas (Borges \& Spink, 2009; Lima \& Romão, 2008; Mesquita \& Pavia, 2015; Risk \& Santos, 2019; Scorsolini-Comin \& Santos, 2012). A maior parte dessas investigações apresenta registro histórico do enredo e caracteriza seus "protagonistas". 
Desde a década de 1970, as telenovelas brasileiras incorporaram uma série de personagens homossexuais que passaram por sucessivas transformações. Em um primeiro momento, esses personagens foram apresentados majoritariamente de modo estereotipado e caricato, como homens efeminados e afetados, que desempenhavam função cômica e secundária na narrativa (Silva, 2015). Posteriormente, passaram a ocupar posições de maior destaque na trama e a apresentar características identificadas pelas normas de gênero como masculinizadas, além de buscarem estabelecer vínculos monogâmicos (Colling, 2013) e reivindicarem visibilidade e respeito ao seu estilo de vida e orientação sexual.

A partir da década de 2010, as diferenças passaram a ser hipervisibilizadas pelas mídias, em especial aquelas relacionadas ao gênero, à sexualidade, à raça e à etnia, fato conjugado com o advento das redes sociais. No âmbito da sexualidade, essa década é marcada pelas polêmicas relacionadas às tentativas de repatologização da homossexualidade, além de ofensivas contra os direitos sexuais (Carrara, 2015) e contra políticas de "reconhecimento das diferenças de gênero e sexualidade", sintetizadas no recrudescimento de pleitos moralizantes por parte de setores conservadores da sociedade brasileira (Balieiro, 2018). No entanto, destacam-se avanços importantes, como o reconhecimento da união estável para casais do mesmo sexo, em maio de 2011, por parte do Supremo Tribunal Federal (STF), além da Resolução no 175/2013 do Conselho Nacional de Justiça (CNJ), que obrigou cartórios brasileiros a celebrarem o casamento civil entre casais do mesmo sexo.

Por serem produzidas na década de 2010 , as telenovelas analisadas no presente estudo circunstanciam esse panorama ao conferirem visibilidade às diferenças nos âmbitos do gênero e da sexualidade, o que justifica a análise de suas formações discursivas. Neste estudo, entende-se que os enunciados não devem ser confundidos com atos de fala, frases e proposições, pois estabelecem condição para a existência dessas estruturas dotando-as de significado. O enunciado, portanto, não se reduz ao objeto ao qual faz referência ou ao sujeito que o produziu, visto que lhes atravessa por meio de suas funções enunciativas (Foucault, 1969/2016). Insistir nessa definição é importante, na medida em que, no texto dramatúrgico, assim como em outros, "um único e mesmo indivíduo pode ocupar, alternadamente, em uma série de enunciados, diferentes posições e assumir o papel de diferentes sujeitos" (p. 113).
Já as formações discursivas referem-se à regularidade, à ordem e às correlações a que estão submetidos os enunciados e que permitem moldá-los, mantê-los e modificá-los, ainda que aparentemente estejam dispersos em diferentes sistemas (Foucault, 1969/2016). A dispersão se caracteriza pela não linearidade dos planos por meio dos quais o sujeito fala, pois no "interior do discurso [o sujeito pode] assumir diferentes estatutos" (Brandão, 2012, p. 35). Na telenovela, por exemplo, a fala de uma personagem pode reconhecer positivamente as diferenças no âmbito da sexualidade a partir de enunciados e fundamentos moralizantes, visto que o discurso é composto de segmentos intermitentes, dinâmicos e não uniformes e, portanto, não se divide em oposições do tipo discurso dominante versus discurso dominado, uma vez que múltiplos elementos e diferentes estratégias o constituem (Foucault, 1976/2009).

Práticas e discursos regulam o sujeito e as relações de gênero que nele se inscrevem. Os estudos queer, diversificada corrente teórica inaugurada em meados da década de 1990 nos Estados Unidos (EUA), constituem importante recurso crítico para análise desses conceitos, pois refutam concepções identitárias e essencialistas a respeito das relações de gênero e da sexualidade (Spargo, 2017), que constituem um padrão comum nos folhetins

O gênero é regulado por expectativas e atribuições padronizadoras das masculinidades e das feminilidades que sustentam relações coerentes e contínuas entre sexo, gênero, prática sexual e desejo. Essas normas definem oposições delimitadas e assimétricas entre "feminino" e "masculino", concebidos como expressões tributáveis à "fêmea" e ao "macho". Nesse sentido, descontinuidades só são assim entendidas em relação a essas expectativas e atribuições, que organizam práticas construtoras de "identidades coerentes por via de uma matriz de normas de gênero coerentes" (Butler, 2008, p. 38), sendo por elas reguladas.

Para o discurso dominante, modalidades de identidade que não seguem essa lógica binária e falocêntrica devem ser suprimidas, pois os gêneros coerentes representam a manifestação de leis culturais que regulam a expressão "natural" da sexualidade. Aqueles que não se conformam a essas diretrizes são considerados falhas ou impossibilidades lógicas e lidos frequentemente como aberrações e expressões de desejos degenerados, como gays, mulheres lésbicas, pessoas trans, dentre outros (Butler, 2008). Em suma, a matriz cultural 
compulsória organiza a relação direta entre sexo (biológico), desejo (psicológico) e gênero (sociocultural), elementos determinados binariamente. Quaisquer sexualidades que não correspondam à relação causal e binária entre os referidos elementos são consideradas ilegítimas, segundo essa lógica.

Diante do exposto, o objetivo deste estudo foi analisar as formações discursivas sobre homossexualidade e família homoparental em telenovelas brasileiras veiculadas em horário nobre, a partir de sua articulação com matrizes culturais, sociais e históricas.

\section{Método}

Trata-se de estudo de caráter qualitativo, baseado na análise da translação/transcrição de cenas de telenovelas produzidas e transmitidas pela maior emissora de televisão do país.

\section{Composição do corpus}

No presente estudo, constituiu-se um corpus específico que demandou a delimitação de um recurso metodológico com a finalidade de captar e analisar o objeto sob investigação. Essa estratégia, eventualmente, pode se prestar a futuras investigações que se proponham à análise de produtos midiáticos envolvendo texto, imagem e som, no formato teledramatúrgico. A construção desse corpus seguiu as orientações de Bauer e Aarts (2002) e Rose (2002).

Assim, foi realizada pesquisa qualitativa e estabelecidos critérios para composição do corpus a partir da seleção de cenas de três telenovelas da década de 2010, que apresentavam personagens gays ao longo de toda a trama. Como as telenovelas são relativamente longas (podendo se estender por mais de uma ou duas centenas de capítulos), comportam diversos núcleos cênicos e numerosos personagens que transitam em tramas periféricas (Pallottini, 2012), optou-se por analisar três produções da faixa das $21 \mathrm{~h}$ da Rede Globo de Televisão (Tabela 1), horário em que a emissora alcança altos índices de audiência. Além disso, as telenovelas que ocupam esse horário da grade de programação são consideradas carro-chefe da emissora, recebendo tratamento diferenciado e investimentos maciços, compatíveis com seu valor comercial. Foram elas: Amor à vida (Carrasco \& Filho, 2013-2014), Império (Silva \& Gomes, Vasconcelos, Binder, 2014-2015) e Babilônia (Braga, Linhares, Braga \& Médicis, Carvalho, 2015).

Tabela 1

Descrição técnica das telenovelas da Rede Globo veiculadas na faixa das 21h, cujas personagens foram destacadas e analisadas.

\begin{tabular}{|c|c|c|c|c|}
\hline Título & Autores & Direção-geral & $\begin{array}{l}\text { Período de } \\
\text { exibiçãao }\end{array}$ & $\begin{array}{l}\text { Quantidade } \\
\text { de capítulos }\end{array}$ \\
\hline Amor à vida & Walcyr Carrasco & Mauro Mendonça Filho & $\begin{array}{c}20 / 05 / 2013 \mathrm{a} \\
31 / 01 / 2014\end{array}$ & 221 \\
\hline Império & Aguinaldo Silva & $\begin{array}{l}\text { Rogério Gomes, } \\
\text { Pedro Vasconcelos, } \\
\text { André Felipe Binder }\end{array}$ & $\begin{array}{c}21 / 07 / 2014 \mathrm{a} \\
13 / 03 / 2015\end{array}$ & 203 \\
\hline Babilônia & $\begin{array}{l}\text { Gilberto Braga, } \\
\text { Ricardo Linhares, } \\
\text { João Ximenes Braga }\end{array}$ & $\begin{array}{l}\text { Maria de Médicis, } \\
\text { Dennis Carvalho }\end{array}$ & $\begin{array}{c}16 / 03 / 2015 \text { a } \\
28 / 08 / 2015\end{array}$ & 143 \\
\hline
\end{tabular}

Nota. Informações extraídas de Entretenimento (c2021).

Buscou-se assegurar que os materiais selecionados fossem homogêneos, haja vista que os meios de comunicação não devem ser confundidos nem tratados de maneira a desconsiderar suas especificidades, isto é, imagens devem ser analisadas à parte, assim como transcrições de diálogos demandam procedimentos apropriados de análise.

\section{Procedimento}

Coleta de dados

No presente estudo, tomou-se como unidade de análise a duração de uma cena, ou seja, trecho de determinado capítulo no qual as personagens homossexuais aparecem e desenvolvem determinada ação 
ou interação. A respeito da translação do material coletado, foram enfatizados aspectos da dimensão narrativa - "transcrição" literal dos diálogos das cenas selecionadas. Como o presente estudo destaca os aspectos discursivos e de que forma esses elementos convencionam discursos sobre homossexualidade, a translação primou pelo registro literal dos diálogos na íntegra, não havendo tanta preocupação em demarcar momentos de hesitação, pausas, silêncios, dentre outros elementos pré-verbais que eventualmente surgissem nas cenas.

Para translação literal e na íntegra foram seguidas as orientações de Rose (2002), que propôs um método para analisar programas de televisão e demais obras audiovisuais. A autora define meios audiovisuais como "amálgama complexo de sentidos, imagens, técnicas, composição de cenas, sequência de cenas e muito mais" (p. 343), complexidade que deve ser ponderada quando se analisam a estrutura e o conteúdo desses materiais. A análise de obras audiovisuais exige aquilo que a autora denomina "transladar", isto é, delimitar critérios para simplificar/transcrever os materiais, sendo que o conteúdo/ forma escolhido é tão importante quanto aquele que foi deixado de lado pelo pesquisador.

Os passos da coleta de dados foram sistematizados da seguinte maneira: a) Leitura atentiva da sinopse das novelas Amor à vida, Império e Babilônia; b) Leitura do resumo de cada capítulo das três novelas, à procura de cenas nas quais as personagens selecionadas estão envolvidas; c) Seleção preliminar de 30 cenas de cada telenovela, de acordo com o tempo diegético da trama (início, meio e fim) para análise; d) Eleição de 15 cenas de cada telenovela a partir de depuração das 30 cenas selecionadas inicialmente. Esse refinamento foi realizado com base nos critérios utilizados para composição do corpus de análise, mencionados anteriormente; e) Translação/transcrição dos diálogos das 15 cenas eleitas de cada novela, considerando aspectos narrativos, totalizando 45 cenas.

\section{Análise dos dados}

Os dados foram analisados conforme o referencial teórico dos estudos queer e dos estudos culturais, além da literatura da área de comunicação sobre telenovelas. A partir desses pressupostos, serão apresentadas e analisadas formações discursivas sobre homossexualidade com base no corpus construído.

\section{Resultados e discussão}

Serão discutidas as formações discursivas referentes às relações afetivas mantidas pelas personagens homossexuais e de que modo o discurso normalizador segmenta a composição de pares amorosos nas telenovelas. Além disso, serão analisadas as formações discursivas sobre a família homoparental e sua articulação com enquadramentos normativos que segmentam e posicionam hierarquicamente as sexualidades. A fim de contextualizar a análise das cenas apresentadas ao longo da presente seção, a trama principal de cada telenovela será descrita, assim como o perfil das personagens homossexuais nelas representadas.

\section{As tramas, as personagens e seus perfis}

Amor à vida, Império e Babilônia se caracterizam como tramas contemporâneas. A primeira é ambientada na cidade de São Paulo (SP) e as demais no Rio de Janeiro (RJ). Amor à vida retrata o drama da família Khoury, composta pelo médico César (Antonio Fagundes), pela dona de casa Pilar (Susana Vieira) e por seus filhos: Félix (Mateus Solano) e Paloma (Paolla Oliveira). Pai e filho mantêm vínculo hostil, marcado por constantes insinuações, por parte de César, sobre a suposta homossexualidade de Félix. Carreirista e ardiloso, Félix deseja usurpar o lugar de onde ele imagina que emana o poder do pai, isto é, a presidência do hospital San Magno. Em boa parte da trama, executará uma série de maldades com intuito de conquistar a direção do hospital e impedir que sua irmã e sua sobrinha herdem a fortuna da família.

Império relata a história da família Medeiros, marcada por traições e pela cobiça em torno dos negócios da joalheria homônima, uma empresa familiar. Paralela à trama da família Medeiros, seguem-se as peripécias de Téo Pereira (Paulo Betti), jornalista e blogueiro sensacionalista, que fora amigo dos tempos de escola do cerimonialista Cláudio Bolgari (José Mayer). Ambos foram alvo de bullying durante a infância e adolescência por não corresponderem aos padrões hegemônicos de masculinidade, ainda que se diferenciem na performance relacionada ao gênero: Téo é efeminado e caricato, ao passo que Cláudio encarna o tipo másculo, "discreto", que não tem intenção de "sair do armário" por usufruir das benesses consagradas ao padrão hegemônico masculino, branco e heterossexual. Os dois se reencontram acidentalmente após muitos anos e, desde então, Téo passa a vasculhar a vida íntima de Cláudio e a publicar em seu blog sen- 
sacionalista notas ferinas e maledicentes que insinuavam sua suposta homossexualidade. Cláudio mantém um relacionamento extraconjugal com o jovem Leonardo (Klebber Toledo), embora procure manter ilibada sua reputação de pai de família e marido exemplar de Beatriz (Suzy Rêgo), a quem declara amar, mantendo um "casamento feliz" de fachada.

Babilônia retrata a história de Estela Marcondes (Nathalia Timberg), que por anos mascarou sua condição de mulher lésbica sob a fachada de um casamento heterossexual. No entanto, cerca de 30 anos antes do momento atual da trama, Estela decidiu se separar do marido para unir-se consensualmente a Teresa Petrucceli (Fernanda Montenegro), renomada advogada criminal, conhecida defensora dos direitos humanos no período da ditadura militar (1964-1985). Estela é mãe de Beatriz (Glória Pires); sua segunda filha faleceu durante o parto. Em virtude da morte da mãe, Rafael (Chay Suede) foi criado pela avó (Estela) e por Teresa, já que o pai o abandonou após o falecimento da esposa. Em núcleo paralelo, Ivan (Marcello Melo Jr.), professor de slackline nas praias cariocas assumidamente gay, ao longo da trama se apaixona por Sérgio (Cláudio Lins), que fora casado por alguns anos com uma mulher e ainda estava "no armário". Porém, a relação entre eles não foi além de um romance passageiro, um breve envolvimento, já que Sérgio se recusa a assumir o relacionamento. Nos capítulos finais, Ivan sofre um acidente que o deixa paraplégico, mote que levará Sérgio a se reaproximar dele. No final da trama, o casal anuncia que pretendem morar juntos, Ivan pede Sérgio em casamento e os dois trocam um recatado "selinho".

No que tange ao perfil das personagens homossexuais presentes nas três telenovelas, é possível dividi-las nas seguintes categorias: a) personagens normalizadas: representadas por homens viris, masculinos e que não apresentam gestos/traços considerados efeminados; é o caso de Leonardo, em Império, e Anjinho, André e Eron, em Amor à vida; b) personagens no armário: em alguns casos se confundem com as personagens normalizadas, são representadas por homens bem posicionados socialmente e com alto nível de escolaridade, solteiros ou casados com mulher, com quem eventualmente têm filhos, e, em paralelo, sustentam uma vida clandestina, mantendo relacionamento secreto com amante/ namorado - Cláudio Bolgari (Império) e Sérgio (Babilônia) se enquadram nessa descrição; c) personagens defenestradas: animam a faceta cômica da telenovela e são constantemente aviltadas em virtude de sua orientação sexual ser escancaradamente exposta à execração pública; Téo Pereira (Império) e Félix (Amor à vida) preenchem esse perfil, ainda que o último tenha desenvolvido outras facetas no decorrer da trama que lhe permitiram não permanecer fixado ao estereótipo da "bicha que dá pinta".

\section{Relações afetivas e homossexualidade}

As relações afetivas representadas nas telenovelas analisadas em geral passam pela expressão de vínculos discretos e normalizados, isto é, que emulam relações heterossexuais. A discrição nas modulações do amor, do desejo e das atitudes das personagens normalizadas é herdeira direta das representações midiáticas ligadas à política assimilacionista, representada por gays e lésbicas que, durante a década de 1980, além de reivindicar equidade, direitos e proteção legal, buscavam associar a homossexualidade a uma "imagem positiva", politicamente neutra, que elevasse a autoestima do grupo e conformasse determinado estilo de vida alinhado ao discurso heteronormativo: "Isso envolvia a crítica a imagens homofóbicas e negativas difundidas na mídia, incluindo os populares estereótipos camp das séries de TV que eram vistos como prejudiciais (queerizantes) à imagem de gays $\mathrm{e}$ lésbicas" (Spargo, 2017, p. 26).

A lógica assimilacionista normatiza personagens como Leonardo, Cláudio, Sérgio, Anjinho, André e Eron. A expressão "discreto", de certo modo, identifica e qualifica essas personagens. Em Império, Leonardo a reitera quando Cláudio se mostra temeroso de que o blogueiro Teodoro Pereira revele sua homossexualidade, tornando pública uma dimensão de sua vida privada que ele tenta manter em segredo. Além disso, parece faltar paixão e lascívia nas cenas entre Cláudio e Leonardo. Não é apenas a "falta de química" entre os dois atores, trata-se de um amor pasteurizado pelo enquadre da tela, pelos cortes realizados pela produção para não "provocar" demasiadamente a audiência, especialmente a parcela mais conservadora do público ou aquela contrária à equiparação de direitos à população LGBTQIA+ (Lésbicas, Gays, Bissexuais, Transexuais, Queer, Intersexo, Assexuais e outras variações) motivada por seus "pânicos morais" (Balieiro, 2018).

Em determinada altura da trama, após fracassar na carreira de ator e se ver sem a tutela financeira de Cláudio, Leonardo chega ao limite extremo da degra- 
dação social e passa a viver nas ruas. Entretanto, a experiência de rua da personagem é edulcorada e não chega a convencer. A própria emissora retirou o peso do desfecho de Leonardo, quando descreveu a cena em tom de brincadeira em postagens nas redes sociais que antecipavam e divulgavam a trama (como estratégia para atrair audiência): "Mendigo gato! Sozinho e deprimido, Leonardo vai virar morador de rua" (Mendigo gato!, 2014).

O padrão brasileiro de telenovela, constituído ao longo do regime de exceção instaurado pela ditadura militar (1964-1985), refletiu a modernização do país a partir do estímulo ao consumo de massa em um universo platinado, sedento por glamour, metropolitano e comprometido com os valores, crenças e atitudes ideais das classes médias e altas (Hamburger, 2011). $\mathrm{Na}$ associação "mendigo gato" há a tentativa de alçar Leonardo ao tipo do "mocinho abandonado", ou melhor, do "príncipe abandonado", que sofre de desamparo pela perda do amado. Por sinal, o ator escalado para interpretar o personagem é loiro, de corpo atlético e olhos azuis. Além disso, nota-se o reflexo das políticas assimilacionistas, destinadas a integrar gays ao universo heterossexual com base em discursos normalizadores, pois o príncipe passará por provações, terá seu caráter testado em uma jornada de sofrimento e dor que coloca sua virilidade à prova e acaba por referendá-la por meio da superação mágica de uma condição de vida marginal.

O universo de glamour ostentado pela telenovela, como exposto por Hamburger (2011), se imbrica no modo como gays costumam ser representados nessas produções. Quando não são "feitos para rir", ou para instilar docilidade e afeto no público, prestam-se à missão de corresponder ao regime heteronormativo, que alça a masculinidade hegemônica aos altos estratos de respeitabilidade e status social. Segundo Connel (2016), a masculinidade hegemônica pode ser definida como configuração de prática que organiza a legitimidade do patriarcado, a garantia da posição dominante dos homens e de subordinação das mulheres, além de corresponder à idealização do "ser homem", ou seja, a modelos enaltecidos do masculino, encarnados em personagens de cinema, atletas, militares, dentre outras figuras icônicas.

As implicações da masculinidade hegemônica repercutem em pesquisa documentada por Beleli (2009), que investigou a visibilidade conferida a gays e mulheres lésbicas nas telenovelas
Páginas da vida (2006) e A favorita (2008), ambas transmitidas no horário nobre pela Rede Globo. Segundo a autora, a associação da homossexualidade à vida no gueto e a posições marginais "vem sendo ressignificada nas novelas e em parte da publicidade, no entanto, os antigos estereótipos podem estar sendo substituídos por outro" (p. 127). As imagens e textos analisados por Beleli evidenciam que tanto a publicidade quanto a teledramaturgia têm valorizado personagens homossexuais que mantêm vínculos afetivo-sexuais estáveis e monogâmicos (namoro, casamento), que convivem apenas com personagens supostamente heterossexuais e que não frequentam espaços tradicionalmente identificados como próprios desse público. No final da trama, essas personagens tendem a encontrar parceiros(as), como Eron, que se apaixona pelo bem-sucedido André, em Amor à vida, e a cumprir promessas de casamento, já que "terminar solteiro" parece estar associado a estigmas e, em geral, é o destino e "castigo merecido" de vilões e vilãs das novelas.

A construção das personagens normalizadas reitera discursos identitários que cumprem a função de legitimar determinado padrão de homossexualidade, formatado e pasteurizado em conformidade com referenciais heteronormativos (Risk \& Santos, 2019). Ainda que o folhetim pareça valorizar a diferença, ao destacá-la, também a molda, coagula e encarcera, o que evidencia, como apontado por Foucault (1969/2016), o quanto o discurso e suas práticas são insidiosos e constroem posições subjetivas a partir de diferentes formas enunciativas, nesse caso, valorizando a homossexualidade confinada ao padrão heteronormativo.

No entanto, se em Amor à vida a diferença é positivada, normalizada, o mesmo padrão não foi alcançado em Babilônia: não apenas o casal lésbico formado por Teresa e Estela foi alvo de críticas severas pelo público conservador, mas também a participação especial da atriz veterana Rogéria, mesmo ela própria se apresentando em entrevistas como "a travesti da família brasileira”. Na novela, Rogéria interpretou a personagem Úrsula Andressa, uma artista trans de projeção internacional. Sua participação acabou sendo limitada aos capítulos finais da trama, em um papel comedido e aquém de seu reconhecido talento artístico, provavelmente por resistência do segmento conservador da audiência a aceitar uma personagem trans(gressiva). Úrsula Andressa, personagem que se confundia com sua intérprete Rogéria, representava 
a diferença que transgride sem reforçar o confronto, e que mesmo assim incomoda a sensibilidade do setor mais conservador, justamente porque imprime autenticidade, traduzida em performance e em arte.

$\mathrm{O}$ discreto potencial transgressor do vínculo amoroso estabelecido entre personagens homossexuais pode ser analisado à luz do que Miskolci (2014) intitula como "regime de visibilidade". Trata-se da

maneira como uma sociedade confere reconhecimento e torna visível certos arranjos amorosos, enquanto controla outras maneiras de se relacionar por meio de vigilância moral, da coibição de sua expressão pública, em suma, pela manutenção dessas outras formas amorosas e sexuais em relativa discrição ou invisibilidade (Miskolci, 2014, p. 62).

Para o autor, trata-se de uma ardilosa relação de dominação e poder, visto que, em vez de exortar prescrições diretas, fundamenta a discriminação depreciativa da diferença em meandros indiretos bastante eficazes em relação ao que é esperado nas relações sociais cotidianas.

Nos capítulos finais de Império, duas cenas subsequentes registram o papel que o regime de visibilidade exerce no reconhecimento de determinadas expressões amorosas e públicas da homossexualidade. Na primeira cena, Leonardo e Cláudio estão correndo pela orla do Rio de Janeiro em um dia de sol. A cena evoca as representações paradisíacas e hollywoodianas da cidade maravilhosa, construídas há décadas com esmero pela Rede Globo. De repente, Cláudio percebe que um paparazzo os observa à distância e os fotografa. Ao longo da trama, ambos foram perseguidos por paparazzi, fotógrafos profissionais que vendiam seus flagras a Téo Pereira, blogueiro ávido por sensacionalismo que constantemente estava à procura de imagens que pudessem ser convertidas em "fofocas" sobre o caso extraconjugal de Cláudio e publicadas em doses homeopáticas nas páginas do blog.

Cláudio: Pera aí... é o que eu tô pensando, é um paparazzo ali?

Leonardo: Eu vou quebrar a máquina desse merda. Cláudio: Deixa, Léo, deixa, Léo. É melhor a gente escancarar de vez, o esforço de se esconder é grande e não vale a pena, vamos lá! (Império capítulo 201).
Os dois se deixam fotografar, sorriem amistosamente e acenam para o "repórter". Na cena seguinte, em seu apartamento, Téo Pereira confere as fotos e diz ao paparazzo que lhe entregou o precioso conteúdo:

Téo: E daí que ele assumiu? Olha, aprenda com o manual dejornalismo deTéo Pereira, quem assume, fica transparente, ou, melhor ainda, fica invisível, só quem não assume é motivo de fofoca, de disse me disse. Se Claudete hétera resolveu exibir o bofe de tanquinho em plena praia para todos saberem que aquela maravilha é só dele, ah, baubau! Ninguém mais vai se interessar por esse assunto. Procure um outro escândalo, porque Claudete hétera agora é o senhor Cláudio assumido e acabou, é finito! (Império - capítulo 201).

A partir do texto e da sucessão de cenas, nota-se que as personagens se comprazem da visibilidade dada ao casal: dois homens, com perfil de galã, brancos, um jovem, outro maduro, que passeiam pela orla carioca exalando saúde e ostentando sua boa forma. Téo Pereira, além de elogiar a virilidade de Leonardo, sentencia que Cláudio, antes tratado jocosamente como Claudete, não está mais “no armário" e, portanto, ao se assumir, não pode mais ser motivo de comentários escusos e tampouco matéria de interesse para seu blog, como ocorreu inúmeras vezes durante a trama. Como os finais dos folhetins eletrônicos, em geral, tendem a ser mal elaborados, segundo Pallottini (2012), ao assumirem publicamente seu relacionamento, Cláudio e Leonardo selam, de modo superficial, o fim do conflito que deu mote a parte da trama.

As injunções do regime de visibilidade também são registradas nas sondagens que a Rede Globo realiza para monitorar a recepção de suas telenovelas enquanto elas estão no ar. No segundo semestre de 2014, pesquisa realizada pela emissora apontou que o público não se manifestava contra a discussão de assuntos relacionados à "comunidade gay" nas telenovelas, no entanto, apresentava resistência em relação a cenas que evidenciassem demonstrações abertas de amor e sexo que envolvessem essas personagens. Segundo a reportagem, a Globo editou e cortou cenas que apresentavam maior aproximação física, inclusive um beijo trocado pelo casal Leonardo e Cláudio Bolgari, em Império (Jimenez, 2014).

Nota-se que o regime de visibilidade, na expressão utilizada por Miskolci $(2014,2015)$, quando 
transposto às telenovelas, ao mesmo tempo em que referenda a expressão de personagens homossexuais (desde que associados aos valores consagrados da família e dos relacionamentos monogâmicos e estáveis), rechaça manifestações que rompem ou cindem com esquemas heteronormativos consagrados, por exemplo, a performance da personagem interpretada por Rogéria em Babilônia. Miskolci afirma que esse regime de visibilidade, longe de ser visto apenas como positivo, prescreve um modo "correto" de estampar publicamente a homossexualidade por meio da mídia, ao mesmo tempo em que cinde as próprias homossexualidades, pois "algumas passaram a ser mais reconhecidas, visíveis e se tornaram modelares, enquanto outras foram mantidas ou relegadas ao repreensível mesmo não sendo necessariamente invisibilizadas" (2015, p. 68). A homossexualidade ainda é vista de modo negativo quando se trata de "homens femininos", travestis e pessoas trans, ou seja, quando apresenta o que o autor chama de "deslocamento de gênero", possivelmente pelo caráter perturbador que essas representações ainda evocam, especialmente nos redutos da população marcados pelo fundamentalismo religioso (Dullius \& Martins, 2020; Freitas, Coimbra, \& Fontaine, 2017; Gaspodini \& Falcke, 2018).

As telenovelas analisadas produzem regimes de verdade que segmentam as personagens homossexuais de modo caricato, além de pasteurizarem as personagens normalizadas cujas expressões afetivas passam a estampar um arremedo de heterossexualidade. Ou seja, a presença das homossexualidades na teledramaturgia brasileira atual, ainda que tenha o efeito de estimular o debate público sobre o tema, reveste-se do argumento identitário que naturaliza e normaliza as sexualidades, sem conseguir colocar em questão os desígnios impositivos da heteronormatividade.

Ao tratar da hegemonia do massivo, Martín-Barbero (2015) reconhece que a televisão se destaca por seu formidável poder de ampliar a tendência de absorver as diferenças, uma vez que esta é a sua estratégia para negá-la. As diferenças serão exibidas em vez de recalcadas, porém livres de seus elementos conflitivos. Até o advento da televisão, nenhum outro meio de comunicação tinha possibilitado o acesso a tamanha variedade de experiências humanas, povos e culturas diferentes. Assim, segundo essa mesma lógica, no caso do presente estudo, nota-se que as personagens homossexuais seguem povoando as telenovelas, oferecendo a visão de uma ampla variedade de experi- ências e situações humanas, mas devidamente domesticadas pelo imaginário que os folhetins eletrônicos organizam e regulam. Mais do que um estilo de vida gay ou uma estilística homossexual, essas personagens cultuam a uniformidade, limpas de conflitos de maior densidade e de problematização das tensões inerentes ao convívio com as diferenças e com a alteridade.

Não apenas nas telenovelas há retóricas normalizadoras sobre os vínculos construídos entre os gays. As pesquisadoras suecas Rosqvist e Andersson (2016) discutem os significados cambiantes do sexo e do amor como estratégia retórica largamente utilizada pela imprensa gay sueca no período 1969-1986, desde a ascensão da contracultura até a emergência da Aids. As autoras argumentam que, durante esse período, os significados da subjetividade homossexual mudaram rapidamente em diversos níveis sociais. Emergiram novos ideais de abertura e, paralelamente, o amor monogâmico se tornou um tema mais dominante na imprensa gay sueca. Essas representações tendiam a excluir as expressões de práticas sexuais baseadas principalmente na obtenção de prazer: houve mudança nas construções discursivas das práticas sexuais, que passaram do enaltecimento do sexo desvinculado para o sexo condicionado ao amor. Também houve a transformação do "amor por amor" para uma valorização do amor condicionado ao casal, ou seja, ao regime monogâmico, mais uma rendição ao padrão heteronormativo.

O estudo de Rosqvist e Andersson (2016) evidencia o quanto é relevante investigar as diferentes produções teledramatúrgicas para compreender as transformações ocorridas na percepção social sobre a homossexualidade e, principalmente, para entender de que modo as construções discursivas contribuem para engendrar certas percepções e representações sobre a sexualidade em diferentes momentos históricos. Desse modo, de acordo com as autoras, os textos difundidos na imprensa gay militante ajudam a construir o cenário de uma homonormatividade.

\section{Família homoparental}

Tanto Amor à vida quanto Babilônia apresentam registro de famílias homoparentais, uma novidade no repertório temático da telenovela brasileira. No caso da primeira, Félix e Niko terminam a trama como pais, além de constituírem vínculo monogâmico estável. Na segunda, Estela e Teresa são mães desde a tenra infância do neto da primeira. Em Amor à vida, 
Félix, por boa parte da trama, apresentou a faceta de vilão e cometeu execráveis maldades. Nos folhetins eletrônicos, em geral, personagens más terminam no ostracismo, morrem ou "ficam sozinhas", isto é, sem par romântico, vaticínio que não se concretizou no caso do personagem. Como Félix expiou seus pecados ao longo da trama, o caminho de sua redenção estava sendo pavimentado e sua reabilitação moral culmina no envolvimento amoroso com Niko que, durante boa parte do enredo, manteve relacionamento estável com Eron. O casal havia tido um filho, Fabrício, com o apoio de Amarilys, cuja paternidade biológica é reconhecida como sendo de Niko. No último capítulo, Félix e Niko passam a cuidar de Fabrício e do filho de César e Aline, morta em uma tentativa frustrada de fuga do presídio em que cumpria pena por seus crimes.

Além da formação da família homoparental, o capítulo em questão apresenta a falsa reconciliação entre pai e filho que, ao longo da telenovela, eram hostis um com o outro. O pai rejeitava abertamente seu filho primogênito por ser gay e afeminado. A derradeira cena do folhetim evoca um pai fragilizado, cego e doente, cujos vínculos familiares foram esfacelados, um déspota que vive o declínio de sua supremacia patriarcal, ao lado de um filho redimido que se converteu em aplicado cuidador, capaz de perdoar o pai e ampará-lo em sua decrepitude, reconstruindo o relacionamento em bases afetivas. $\mathrm{O}$ happy end é ocupado não tanto pelo aguardado "beijo gay" entre Félix e Niko, mas, sobretudo, pelo enlace das mãos de pai e filho à beira-mar, região litorânea e, portanto, liminar. Essa derradeira cena da novela, ao som da Quinta Sinfonia de Gustav Mahler, é alusiva ao filme Morte em Veneza (Mort à Venise, Itália, França, 1971), uma história sobre o efeito arrebatador da paixão homoerótica, clássico dirigido por Luchino Visconti, um esteta da decadência da aristocracia europeia.

Niko, apelidado de "Carneirinho" por Félix, oferece a ele a possibilidade de viver um "outro destino", a saber, a experiência da parentalidade e da composição da família homoparental monogâmica. O vilão abandona suas maldades e veleidades, amadurece, torna-se "pai de família", "bom tio", "bom filho", dentre outras qualificações próprias dos finais milagrosos dos folhetins. Na cena trasladada, extraída dos capítulos finais de Amor à vida, fica implícito que as personagens mantiveram relações sexuais pela primeira vez e, ao tomar café da manhã, trocam olhares afetuosos, dão-se as mãos em um gesto de terna delicadeza e conversam sobre o vínculo que estão construindo. Embora o interesse entre ambos tenha surgido espontaneamente e sido costurado pelo autor desde meados da novela, apenas nos capítulos finais ambos efetivamente "ficam juntos".

Félix: Agora só porque. . . rolou, você acha que já pode fazer planos, mudar minha vida toda? Não, já sou bem crescidinho, já posso tomar minhas próprias decisões e dar um rumo pra minha vida, viu? Niko: Você pode, realmente, tomar suas próprias decisões, é uma capacidade, que. . . realmente sobra, né?

Félix: Por quê?

Niko: Porque você quer sair de São Paulo, você não sabe para onde, você não sabe nem o que você vai fazer, Félix. Eu tô te oferecendo um destino, Félix. A única coisa que importa é se você gosta de mim.

Félix: Claro que eu gosto, eu gosto de você, Carneirinho. Mas é tanta coisa na minha cabeça... (Amor à vida - capítulo 219).

A família homoparental, formada por Niko e Félix, parece subverter o dispositivo da sexualidade (Foucault, 1976/2009), em particular, a aliança tradicional formada pela mãe, dedicada aos cuidados dos filhos, e pelo pai, zeloso da ordem e da honra, associada aos conselhos médicos e pedagógicos que docilizam os corpos infantis. No entanto, ainda que no caso sejam duas personagens homossexuais, pais de duas crianças, a forma de organização da família - Niko, doce e dedicado aos filhos, Félix, dedicado ao trabalho - reproduz o modelo nuclear heterossexual e seus preceitos (Cecílio, Scorsolini-Comin, \& Santos, 2013; Nascimento, Scorsolini-Comin, Fontaine, \& Santos, 2015; Rosa, Melo, Boris, \& Santos, 2016). Nesse caso, a família homoparental, embora represente certa distensão dos costumes, é regulada pelas relações de poder inscritas no dispositivo da sexualidade (Baptista-Silva, Hamann, \& Pizzinato, 2017; Lira \& Morais, 2020; Marques \& Sousa, 2016; Santos, Scorsolini-Comin, \& Santos, 2013).

Regulação, para Butler (2014), "é aquilo que constrói regularidades, mas é também, seguindo Foucault, um modo de disciplina e vigilância das formas modernas de poder; ela não simplesmente constrange e nega e, portanto, não é meramente uma forma jurídica de poder" (p. 271). Regulação, portanto, implica normalizar, pois a norma institui um padrão de referência, 
por exemplo, aqueles que transgridem modelos de masculinidade continuam sendo entendidos segundo esses parâmetros. Assim, ao expandir o raciocínio de Butler, aventa-se que as famílias homoparentais, ainda que apresentem particularidades, seguem reguladas pelo parâmetro heteronormativo. Não é à toa que, segundo a autora, as leis do Estado sobre adoção por gays ou lésbicas, ao mesmo tempo que impõem uma série de restrições, estabelecem determinado ideal de paternidade/maternidade e do que é considerado um parceiro legítimo.

Butler (2014) considera que a regulação, ao instituir padrões de masculinidade e feminilidade, define quais sujeitos neles se enquadram e quais os transgridem. Trata-se do regime de "inteligibilidade social", que se presta a definir determinadas vidas como dignas e legítimas em detrimento de outras (Martínez-Guzmán, \& Íñiguez-Rueda, 2017). A questão que se aponta, no caso do presente estudo, é o quanto as telenovelas analisadas, de certo modo, difundem determinados pleitos do movimento LGBTQIA+, tais como a regulamentação legal da adoção de crianças por casais do mesmo sexo e o direito à expressão pública de afeto, ao mesmo tempo que se pautam em tipos e caricaturas para construir versões midiáticas da homossexualidade. Em outra obra, Butler (2016) afirma que os enquadramentos normativos não levam em consideração as múltiplas identificações que constituem o sujeito, pois tendem a restringi-lo com base em categorias classificatórias, por exemplo, homossexuais versus heterossexuais, homens versus mulheres, dentre outras figurações de antagonismos binários.

Segundo Harlap (2017), ao longo da década de 2000, as representações de sujeitos que não estão em conformidade com a heteronormatividade se tornaram cada vez mais visíveis na televisão israelense, fazendo-se presentes nos vários canais e nos diversos gêneros narrativos dos programas televisivos. Por outro lado, nos anos 2010, esse cenário sofreu mudança considerável, já que muitos programas passaram a apresentá-los como pais. É interessante cotejar essa experiência com o que é observado na televisão brasileira no mesmo período. Se, por um lado, houve considerável incremento e diversificação das representações de personagens não heterossexuais nas telenovelas, isso não alcançou a visibilidade da família homoparental. Em Israel, ao contrário, nos anos 2010 as narrativas televisivas costumam apresentar a paternidade homossexual como um fenômeno positivo e, por vezes, até mais bem-sucedido do que a paternidade heterossexual, como evidencia o estudo de Harlap.

\section{Considerações finais}

Como a construção da personagem na telenovela, independentemente de sua orientação afetivo-sexual, é na maior parte das vezes extremamente linear e superficial, não há razões para esperar que no futuro os contornos dados às figuras não heterossexuais sejam esculpidos em profundidade, porque os avanços certamente serão limitados pelos cânones do gênero. A telenovela é um produto comercial, que se sustenta com personagens unidimensionais e geralmente empobrecidos do ponto de vista dramatúrgico, enredados em tramas maniqueístas que opõem o bem e o mal e que tendem a se repetir ad nauseam. A fábrica de ilusões é regida por um jogo de "cartas marcadas". Por detrás dos bastidores, no lado avesso do "espelho mágico", não se pode desvincular a produção de certos modos preferenciais de subjetivação das homossexualidades pela via das telenovelas produzidas pela emissora que, ao longo das últimas décadas, contribuiu para a construção da hegemonia conservadora, utilizada para consolidar sua influência em todas as instâncias de poder do país.

Como obra aberta, a telenovela reverbera o gosto médio da audiência e se reconfigura ao sabor da aceitação ou rejeição do público, meticulosamente aferidas por pesquisas de opinião, ao mesmo tempo que contribui ativamente para condicionar os conteúdos que esse mesmo público aceita e reconhece como normativo. Em decorrência das mudanças operadas nas relações de gênero e no ordenamento social da sexualidade a partir da década de 1960 no Ocidente, é perfeitamente factível esperar que as temáticas da existência não heterossexual possam finalmente ser expressas em personagens minimamente complexas e dotadas de interioridade consistente. Todavia, a análise das telenovelas Amor à vida, Império e Babilônia evidenciou que persistem clichês, estereótipos e lugares comuns na construção teledramatúrgica do homossexual masculino, como a onipresença da "bicha louca", do gay afeminado e sexualmente infantilizado, do "viado" másculo, malhado e calculista, do entendido lascivo que transita languidamente pelo gueto com a cumplicidade das sombras, entre outras figurações depreciativas, estereotipadas e ofensivas conforme os perfis categorizados no presente estudo. 
Nota-se, portanto, que as telenovelas - ou simplesmente novelas, como são conhecidas no imaginário social brasileiro - podem ser potentes instrumentos de normalização e regulação de modos de ser gay, inclusive encarnando o icônico e cobiçado papel de vilão e imprimindo certa ousadia, embalada pretensiosamente como inovação - mesmo que de qualidade duvidosa, como Félix, já que a personagem foi consagrada como protagonista de Amor à vida. A questão que se coloca aqui é: até que ponto a diferença como é posta nas telenovelas está apenas reproduzindo discursos normativos e reforçando a heteronormatividade (por categorias acusatórias como a "bicha má", a "bicha pobre", a "bicha pão com ovo" etc.), em vez de produzir uma potencialização das sexualidades, a partir de um olhar descolonizado e do diálogo solidário com as multiplicidades de corpos insurgentes?

São inúmeros os desafios da promoção dos direitos humanos da população não heterossexual. Temas candentes na contemporaneidade, como a união civil de pessoas do "mesmo sexo", índices alarmantes de violência contra a população LGBTQIA+, discriminação nas escolas e no mercado de trabalho, vulnerabilidade à Aids, estigmatização - inclusive pelo setor de saúde - e marginalização de certos estilos de vida, ainda são questões negligenciadas ou que estão longe de ser abordadas pelas personagens homossexuais retratadas nas telenovelas. Há muitos "armários" e barreiras a serem rompidas e é importante que a teledramaturgia se sinta desafiada a testar os limites com que tem circunscrito esses temas em suas produções, de modo a tornar exequíveis representações que desestabilizem as retóricas normalizadoras.

Parece que ainda há um longo caminho a ser percorrido até que se possa assistir a uma preocupação genuína com a necessidade de construir imagens problematizadoras das diversas facetas das homossexualidades, com personagens que possibilitem pensar a dimensão dos afetos e da intimidade da vida familiar desse grupo, de suas preocupações cotidianas com os desafios enfrentados na educação dos filhos, do acesso a empregos de qualidade e serviços de saúde realmente inclusivos e humanizados, da conquista de direitos básicos de cidadania contra atos reiterados de violação e discriminação motivados por orientação sexual ou identidade de gênero. Ademais, as questões instigadas pela discussão sobre as interseccionalidades - raça, etnia, classe, gênero e seus desdobramentos também têm sido sistematicamente descuradas no desenho unidimensional das personagens não heterossexuais nas telenovelas, tema sugestivo de futuras pesquisas.

\section{Referências}

Balieiro, F. F. (2018). Não se meta com meus filhos: A construção do pânico moral da criança sob ameaça. Cadernos Pagu, (53), e185306. http://doi.org/10.1590/18094449201800530006

Baptista-Silva, G., Hamann, C., \& Pizzinato, A. (2017). Marriage in prison: Identity and marital agencies in a LGBT wing. Paidéia, 27(supl. 1), 376-385. https://doi.org/10.1590/1982-432727s1201702

Bauer, M. W., \& Aarts, B. (2002). A construção do corpus: Um princípio para a coleta de dados qualitativos. In M. W. Bauer, \& G. Gaskell (Orgs.), Pesquisa qualitativa com texto, imagem e som: Um manual prático (pp. 39-63). Vozes.

Beleli, I. (2009). Eles(as) parecem normais: Visibilidade de gays e lésbicas na mídia. Revista Bagoas, 3(4), 113-130.

Borges, L. S., \& Spink, M. J. P. (2009). Repertórios sobre lesbianidade na mídia televisiva: Desestabilização de modelos hegemônicos. Psicologia \& Sociedade, 21(3), 442-452. http://doi.org/10.1590/S0102-71822009000300018

Braga, G., Linhares, R., Braga, J. X. (Autores), \& Médicis, M., Carvalho, D. (Direção-geral). (2015). Babilônia [Telenovela]. TV Globo.

Brandão, H. H. N. (2012). Introdução à análise do discurso. Ed. Unicamp.

Butler, J. (2008). Problemas de gênero: Feminismo e subversão da identidade. Civilização Brasileira.

Butler,J. (2014). Regulações de gênero. CadernosPagu, (42),249-274.http://doi.org/10.1590/0104-8333201400420249

Butler, J. (2016). Quadros de guerra: Quando a vida é passivel de luto. Civilização Brasileira.

Carrara, S. (2015). Moralidades, racionalidades e políticas sexuais no Brasil contemporâneo. Mana, 21(2), 323-345. http://doi.org/10.1590/0104-93132015v21n2p323

Carrasco, W. (Autor), \& Filho, M. M. (Direção-geral). (2013-2014). Amor à vida [Telenovela]. TV Globo. 
Cecílio, M. S., Scorsolini-Comin, F., \& Santos, M. A. (2013). Produção científica sobre adoção por casais homossexuais no contexto brasileiro. Estudos em Psicologia, 18(3), 507-516.

Colling, L. (2013). Mais visíveis e mais heteronormativos: A performatividade de gênero das personagens não-heterossexuais nas telenovelas da Rede Globo. In L. Colling, \& D. Thürler (Orgs.), Estudos e políticas do CUS: Grupo de pesquisa cultura e sexualidade (pp. 87-110). Ed. UFBA.

Connel, R. W. (2016). Gênero em termos reais. nVersos.

Dullius, W. R., \& Martins, L. B. (2020). Training needs measure for health care of the LGBT+ public. Paidéia, 30, e3034. https://doi.org/10.1590/1982-4327e3034

Entretenimento: Tramas emocionantes, programas que marcaram época. (c2021). Memória Globo. https://memoriaglobo.globo.com/entretenimento/novelas/

Foucault, M. (2009). História da sexualidade I: A vontade de saber. Graal. (Trabalho original publicado em 1976)

Foucault, M. (2016). A arqueologia do saber. Forense Universitária. (Trabalho original publicado em 1969)

Freitas, D. F., Coimbra, S., \& Fontaine, A. M. (2017). Resilience in LGB youths: A systematic review of protection mechanisms. Paidéia, 27(66), 69-79. https://doi.org/10.1590/1982-43272766201709

Gaspodini, I. B., \& Falcke, D. (2018). Sexual and gender diversity in clinical practice in Psychology. Paidéia, 28, e2827. https://doi.org/10.1590/1982-4327e2827

Hamburger, E. I. (2005). O Brasil antenado: A sociedade das novelas. Jorge Zahar.

Hamburger, E. I. (2011). Telenovelas e interpretações do Brasil. Lua Nova, (82), 61-86.

Harlap, I. (2017). The new normative: Gay fatherhood on Israeli television. GLQ: A Journal of Lesbian and Gay Studies, 23(4), 559-587. https://doi.org/10.1215/10642684-4157523

Jimenez, K. (2014, 21 de setembro). Volta para o armário. Folha de S.Paulo. http://feeds.folha.uol.com.br/fsp/ ilustrada/186632-volta-para-o-armario.shtml

Kellner, D. (2001). A cultura da mídia-estudos culturais: Identidade e política entre o moderno e o pós-moderno. Edusc.

LaPastina, A., \& Joyce, S. (2014). Changing GLBTQ representations: The sexual other in Brazilian telenovelas. Lumina: Revista do Programa de Pós-Graduação em Comunicação, 8(2), 1-27. https://doi.org/10.34019/ 1981-4070.2014.v8.21165

Lima, C. C. K., \& Romão, L. M. S. (2008). Sentidos de homossexualidade em uma novela: Confronto de formações discursivas. Linguasagem, 3, 1-14.

Lira, A. N., \& Morais, N. A. (2020). Psychosocial adjustment profiles of gay and lesbian individuals involved in marital relations: A cluster-based analysis. Paidéia, 30, e3013. https://doi.org/10.1590/1982-4327e3013

Marques, F. D., \& Sousa, L. (2016). Portuguese older gay men: Pathways to family integrity. Paidéia, 26(64), 149-159. https:// doi.org/10.1590/1982-43272664201602

Martín-Barbero, J. (2015). Dos meios às mediações: Comunicação, cultura e hegemonia. Ed. UFRJ.

Martínez-Guzmán, A., \& Íñiguez-Rueda, L. (2017). Discursive practices and symbolic violence against the LGBT community within the university setting. Paidéia, 27(suppl. 1), 367-375. https://doi.org/10.1590/ 1982-432727s1201701

Mendigo gato! Sozinho e deprimido, Leonardo vai virar morador de rua. (2014, 15 de outubro). GShow. http://gshow.globo.com/novelas/imperio/extras/noticia/2014/10/mendigo-gato-sozinho-e-deprimidoleonardo-vai-virar-morador-de-rua.html

Mesquita, A. M., \& Pavia, C. F. (2015). A família homoparental na ficção televisiva: As práticas narrativas do Brasil e da Espanha como relatos das novas representações afetivo-amorosas. Dados, 58(1), 223-255. http://doi.org/10.1590/00115258201543

Miskolci, R. (2014). Negociando visibilidades: Segredo e desejo em relações homoeróticas masculinas criadas por mídias digitais. Revista Bagoas, 8(11), 51-78.

Miskolci, R. (2015). Discreto e fora do meio: Notas sobre a visibilidade sexual contemporânea. Cadernos Pagu, (44), 61-90. http://doi.org/10.1590/1809-4449201500440061 
Psicologia: Ciência e Profissão 2021 v. 41 (n.spe 3), e189811,1-15.

Nascimento, G. C. M., Scorsolini-Comin, F., Fontaine, A. M. G. V., \& Santos M. A. (2015). Relacionamentos amorosos e homossexualidade: Revisão integrativa da literatura. Temas em Psicologia, 23(3), 547-563. http://dx.doi.org/ 10.9788/TP2015.3-03

Pallottini, R. (2012). Dramaturgia de televisão. Perspectiva.

Peret, L. E. (2005). De “O Rebu” à “América”: 31 anos de homossexualidade em telenovelas da Rede Globo (19742005). Contemporânea, 3(2), 33-45.

Risk, E. N., \& Santos, M. A. (2019). A construção de personagens homossexuais em telenovelas a partir do cômico. Revista Subjetividades, 19(2), e8801. http://doi.org/10.5020/23590777.rs.v19i2.e8801

Rosa, J. M., Melo, A. K., Boris, G. D. J. B., \& Santos, M. A. (2016). A construção dos papéis parentais em casais homoafetivos adotantes. Psicologia: Ciência e Profissão, 36(1), 210-223. https://doi.org/10.1590/1982-3703001132014

Rose, D. (2002). Análise de imagens em movimento. In M. W. Bauer, \& G. Gaskell (Orgs.), Pesquisa qualitativa com texto, imagem e som: Um manual prático (pp. 343-364). Vozes.

Rosqvist, H. B., \& Andersson, C. (2016). Bad sex, good love: Homonormativity in the Swedish gay press, $1969-86$. GLQ: A Journal of Lesbian and Gay Studies, 22(1), 33-54. http://doi.org/10.1215/10642684-3315325

Sadek, J. R. (2008). Telenovela: Um olhar do cinema. Summus.

Santos, Y. G. S., Scorsolini-Comin, F., \& Santos, M. A. (2013). Homoparentalidade masculina: Revisando a produção científica. Psicologia: Reflexão \& Crítica, 26(3), 572-582. https://doi.org/10.1590/S0102-79722013000300017

Scorsolini-Comin, F., \& Santos, M. A. (2012). Insensatos afetos: Homossexualidade e homofobia na telenovela brasileira. Barbarói, (36), 50-66.

Silva, A. (Autor), \& Gomes, R., Vasconcelos, P., \& Binder, A. F. (Direção-geral). (2014-2015). Império [Telenovela].TV Globo.

Silva, F. N. (2015). Bicha nem tão má: Representações da homossexualidade na telenovela Amor à Vida (Dissertação de mestrado, Pontifícia Universidade Católica do Rio Grande do Sul). Repositório Institucional PUCRS. http://hdl.handle.net/10923/7112

Spargo, T. (2017). Foucault e a teoria queer. Autêntica.

\section{Eduardo Name Risk}

Doutor em Psicologia pela Faculdade de Filosofia, Ciências e Letras de Ribeirão Preto da Universidade de São Paulo (FFCLRP-USP). Professor do Departamento de Psicologia do Centro de Educação e Ciências Humanas da Universidade Federal de São Carlos (CECH-UFSCar), São Carlos-SP, Brasil.

E-mail: eduardorisk@ufscar.br

(D) https://orcid.org/0000-0001-7290-2597

\section{Manoel Antônio dos Santos}

Livre-docente em Psicoterapia Psicanalítica. Professor Titular da FFCLRP-USP, Ribeirão Preto - SP. Brasil.

E-mail: masantos@ffclrp.usp.br

(D) https://orcid.org/0000-0001-8214-7767

Este estudo foi realizado com o apoio da Coordenação de Aperfeiçoamento de Pessoal de Nível Superior (Capes) (Código de Financiamento 001) por meio da concessão de bolsa de doutorado ao primeiro autor, sob orientação do segundo autor. Também contou com apoio do Conselho Nacional de Desenvolvimento Científico e Tecnológico Brasil (CNPq) por meio de Bolsa de Pós-Doutorado Junior (Processo no 150699/2018-2) concedida ao primeiro autor e Bolsa de Produtividade em Pesquisa, nível 1A, concedida ao segundo autor.

Endereço para correspondência:

Universidade Federal de São Carlos, Centro de Educação e Ciências Humanas, Departamento de Psicologia. Rodovia Washington Luis, km 235, Caixa postal 676. CEP: 13565-905. São Carlos - SP. Brasil. 
Recebido 05/01/2018

Aceito 13/03/2019

Received $01 / 05 / 2018$

Approved 03/13/2019

Recibido 05/01/2018

Aceptado 13/03/2019

Como citar: Risk, E. N., \& Santos, M. A. (2021). Formações discursivas sobre homossexualidade e família homoparental em telenovelas brasileiras. Psicologia: Ciência e Profissão, 41 (n.spe 3), 1-15. https:// doi.org/ 10.1590/1982-3703003189811

How to cite: Risk, E. N., \& Santos, M. A. (2021). Discursive formations on homosexuality and homoparenthood in Brazilian soap opera. Psicologia: Ciência e Profissão, 41 (n.spe 3), 1-15. https://doi.org/10.1590/1982-3703003189811

Cómo citar: Risk, E. N., \& Santos, M. A. (2021). Formaciones discursivas sobre homosexualidad y familia homoparental en telenovelas brasileñas. Psicologia: Ciência e Profissão, 41 (n.spe 3), 1-15. https:/ /doi.org/ $10.1590 / 1982-3703003189811$ 